\title{
QUE TREINTA AÑOS NO ES NADA...O SÍ: EL ABANDONO CONTINUADO DE LOS BARRIOS DE LA PERIFERIA HISTÓRICA
}

\author{
Isabel González (Dra. Arquitecta - Profesora asociada DUyOT)
}

Desde 1985 resulta difícil destacar un único evento o suceso urbano, máxime cuando este periodo de treinta años, coincide no sólo con la transición entre los dos siglos sino con la consolidación del modelo neoliberal más conocido como globalización, con importante repercusiones territoriales y urbanas y que realmente ha supuesto el declive de todo el modelo desarrollado en Europa desde finales de la Segunda Guerra Mundial, que parece haberse convertido en un espejismo, en la ilusión de una sociedad con cierto grado de prosperidad y con sistemas de regulación que si no pretendían la igualdad, al menos aspiraban a una cierta cohesión social con menor desigualdad (aunque fuese en pos de una paz social que evitase alternativas más revolucionarias que cuestionarán el sistema). A esta dificultad de partida se añade la propia experiencia profesional y académica que abarca un periodo menor del tratado y que me obliga a recurrir, más que a la experiencia a mi propio imaginario urbanístico para ese primer decenio 1985-1995. Esta reflexión, además, se centrará en el territorio que más conozco: la región madrileña. En cualquier caso, si me parece interesante destacar el comienzo de este periodo, que podría quedar representado por el tan mitificado Plan General del 85 de Madrid, pero también y sobre todo, por la consolidación del proceso de recualificación urbana centrado en la implementación de dotaciones urbanas (equipamientos, zonas verdes y servicios) y la mejora de los barrios iniciado con los primeros Ayuntamientos democráticos que representaría una cierta consolidación del incipiente Estado de Bienestar y tendría su ejemplo más paradigmático en el proceso de Remodelación de Barrios de Madrid (1979-1989). Un proceso que no ha sido suficientemente divulgado ni transmitido a los futuros urbanistas ni arquitectos en nuestras escuelas y que debería incorporarse por su carácter innovador en aspectos tan actuales como la gobernanza y la participación (conceptos también míticos de nuestro actual imaginario) donde se produjo esa tan deseada, por excepcional, convergencia de actores e intereses entre vecinos, técnicos y poderes públicos y donde las reivindicaciones legítimas de una mejor calidad de vida se tradujeron en propuestas concretas bastante exitosas en algunos aspectos (al menos desde el punto de vista de la calidad residencial y del reasentamiento de los vecinos en sus propios barrios). Este proceso, con sus luces y sombras, intentó intervenir y remodelar toda una periferia social y física que había crecido al albur de desarrollismo de los años 1960 y 1970 y que fue reconocido por Naciones Unidas en el Concurso de Buenas Prácticas en 1996.

Con objetivos y estrategias completamente diferentes nos encontramos las propuestas de la década posterior, ya en pleno "milagro económico" caracterizado por la tan conocida burbuja inmobiliaria y que, a mi entender, se apoya fundamentalmente en un desprecio absoluto por la ciudad existente como construcción colectiva y con un valor de uso en sí misma y se interesa exclusivamente por la ciudad y el territorio como valor de cambio e inversión dentro de un contexto económico global de escala planetaria. Así el modelo territorial se centra en un 
desarrollo inusitado de las infraestructuras de comunicación que a modo de red permita conectar los nuevos polos de concentración de capital e inversión. Los intersticios de este territorio red no interesan y así gran parte de la ciudad existente, fundamentalmente los barrios alejados de los centros de prestigio y representación, se abandonan a su suerte. Se apuesta por un desarrollo urbano incesante que alimente la máquina inmobiliaria con independencia de las necesidades reales. El resultado es un territorio invadido por innecesarias y costosas infraestructuras del que cuelgan piezas especializadas, "autistas", internamente homogéneas y simples que precisamente como carecen de las cualidades básicas para denominarse ciudad necesitan que se incluya en su denominación el apelativo de ciudad: Ciudad del $\mathrm{BSCH}$, Ciudad de la Justicia, Ciudad del BBVA, Ciudad Deportiva del Real Madrid, Ciudad Valdeluz. Todo ello apoyado en unos poderes públicos bien adiestrados que despliegan un aparato legislativo y unos instrumentos de planeamiento también adaptados a los objetivos perseguidos y donde su papel regulador se va difuminando hasta transmutarse en mero árbitro complaciente, en el mejor de los casos, o activo especulador, en otros (véase el caso de las famosas Cuatro Torres localizadas al norte de la Castellana en las antigua instalaciones Deportivas del Real Madrid).

El objetivo decían era posicionar la ciudad de Madrid dentro del ranking de ciudades, centros mundiales de capital, inversión y negocio. Evidentemente Madrid no podía aspirar a la liga de honor pero si creían que podían formar parte de una honrosa segunda división de ciudades europeas. Para ello, en línea con el modelo anteriormente descrito, era necesario recurrir al marketing urbano e ir colocando piezas de autor de reconocido prestigio internacional, desperdigadas por la ciudad pero conectadas a la red e incluso recurrir un gran acontecimiento como el gran espejismo de los Juegos Olímpicos, etc. En una reunión entre técnicos municipales y arquitectos en el Ayuntamiento de Madrid, fui testigo de una intervención de un insigne colega, que probablemente forme parte de alguno de los "think tanks" tan de moda ahora, que sin un ápice de rubor afirmó que en Londres, en París no se podía vivir ciertamente pero era donde ocurría todo y eso era a lo que tenía que aspirar la ciudad de Madrid. Para el escándalo de la mayoría de los técnicos municipales que lidian día a día con la gestión municipal, se estaba alardeando públicamente de un sinsentido no deseable pero además inalcanzable por irreal. En estos momentos es cuando cualquiera con cierto sentido común piensa "en que manos estamos". Hago aquí un inciso para afirmar que afortunadamente la Administración está llena de grandes profesionales que se mantienen firmes intentado aguantar la marea que les pretende arrastrar. Y como todo sueño o pesadilla llegó el momento de despertar y al hacerlo descubrimos la, por otro lado anunciada, crisis económica con el consabido pinchazo de la burbuja inmobiliaria y nos encontramos inmersos en un proceso sin precedente $y, a$ mi entender, sin posibilidad de remontada aunque algunos auguren la salida, porque se trata de una crisis sistémica que debería suponer el replanteamiento de todo el modelo. Desde el punto de vista territorial y urbano, las consecuencias de la crisis son evidentes y de todos conocidas y se resumen de forma fácil: la imposibilidad de mantener un modelo territorial y urbano del todo insostenible desde el punto de vista económico, social y ambiental cuya funcionalidad depende de una elevadísima movilidad que había podido funcionar gracias a un petróleo barato y que producía ciertas "externalidades" sociales y ambientales que el sistema creía poder soportar. Desde el momento en que las bases que sustentaban el modelo fallan, el modelo pasa de ineficiente a inviable. 
Y en medio de todo esto, nos encontramos con nuevos desarrollos residenciales fantasmas, suelos ocupados a medio urbanizar, infraestructuras infrautilizadas y de elevado coste de mantenimiento, viviendas vacías y familias sin vivienda, desahucios y... los barrios de la periferia histórica de Madrid y sus ciudadanos, resistiendo y adaptándose como han podido, echando mano de una cualidad, la resiliencia (otro término que ha comenzado a mitificarse) que está relacionado con algunas características de nuestros tejidos urbanos consolidados, la variedad articulada de sus elementos que favorece una alta complejidad en un área relativamente pequeña (elevada accesibilidad) y que facilita la diversidad de usos, población y actividades. Ahora bien, el modelo ineficaz y excluyente que hemos construido en las últimas décadas ha ido destruyendo la diversidad y debilitando la resiliencia de los barrios e incluso destruyendo los más vulnerables, los que no habían conseguido una suficiente complejidad que les permitiera sostenerse. Por tanto hay que empezar a articular un nuevo relato entre todos que permita reconstruir el modelo territorial y urbano e intentar volver a confluir actores (políticos, técnicos y ciudadanos) si es que realmente alguna vez se produjo esa convergencia. Con mucha frecuencia se habla de la crisis del planeamiento, de la ineficacia del instrumento para adecuarse a la nueva realidad, de la necesidad de instrumentos más ágiles y actuales, de la excesiva legislación urbanística y sectorial, etc... pero, a mi entender, el verdadero problema es la falta de interés real por la ciudad y por el territorio, por mucho que se hable continuamente de su profunda crisis. Por parte de los poderes públicos, reiteradamente ha hecho dejación de su función principal al olvidar algunos de sus objetivos fundamentales: el fin social del suelo (y por extensión del territorio y la ciudad) y el bienestar de la totalidad de sus ciudadanos.

Por parte de la población en general, existe una cada vez mayor porción que bastante tiene con sufrir las consecuencias del modelo y sobrevivir; otros menos, que se creían ganadores y que ven como todo era un espejismo, fruto del narcóticas promesas de clase media y que, día a día, pierden no sólo sus cada vez más exiguos emolumentos entre hipotecas y gasolina sino algo fundamental e irremplazable, su tiempo vital diario, en costosos desplazamientos por el territorio red para satisfacer las necesidades más básicas. Por parte de los agentes económicos, que siguen considerando la ciudad y el territorio como un bien exclusivamente económico donde campar sin restricciones como antiguos señores feudales. Por parte de los técnicos, arquitectos y urbanistas, que se debaten entre la reflexión improductiva desde los altares del Conocimiento y la Academia, el narcisismo del artista que se regocija en la maestría de su obra arquitectónica y la mera supervivencia de un oficio, en otros tiempos prestigioso y reconocido, y que ahora apenas permite sobrevivir a unos pocos. Evidentemente hay luces entre tanta sombra como las iniciativas desde debajo, de empoderamiento de la ciudadanía (más conceptos míticos), nuevos temas sobre los que se están trabajando como la regeneración urbana integrada, los planes de barrio, etc... pero siguen siendo propuestas muy locales, en ocasiones demasiado alternativas para su generalización. Se necesita una articulación y un impulso desde los poderes públicos.

En este punto, el planeamiento como instrumento "omnicompresivo" sigue siendo necesario, transformado, actualizado hacia la intervención en la ciudad y el territorio porque la visión integral es, más que nunca, imprescindible. Recuperar y rehabilitar los barrios desde la ciudad y la ciudad desde o barrios. 